Article

\title{
Active Vibration Isolation of a Diesel Generator in a Small Marine Vessel: An Experimental Study
}

\author{
Tiejun Yang ${ }^{1}$, Lei $\mathrm{Wu}^{1}{ }^{1}$, Xinhui Li ${ }^{1}{ }^{*}$, Minggang Zhu ${ }^{1}$, Michael J. Brennan ${ }^{2}$ and Zhigang Liu ${ }^{1}$ \\ 1 Institute of Vibration and Noise Control, Harbin Engineering University, Harbin 150001, China; \\ yangtiejun@hrbeu.edu.cn (T.Y.); wulei_1990@foxmail.com (L.W.); zhuminggang@hrbeu.edu.cn (M.Z.); \\ liuzhigang@hrbeu.edu.cn (Z.L.) \\ 2 Departamento de Engenharia Mecânica, Universidade Estadual Paulista (UNESP), São Paulo 15385, Brazil; \\ mjbrennan0@btinternet.com \\ * Correspondence: lixinhui@hrbeu.edu.cn; Tel.: +86-0451-8258-9199
}

Received: 2 April 2020; Accepted: 24 April 2020; Published: 26 April 2020

\begin{abstract}
An active vibration isolation system is retrofitted to a diesel generator set in a tugboat to determine the effectiveness of such a system in a realistic practical environment. The system consists of six bespoke inertial actuators chosen to make minimal modifications to the machinery arrangement, and a DSP-based controller. Six accelerometers are collocated with the actuators on the top of six isolators to act as error sensors, and six accelerometers are placed below the isolators to give a measure of the global vibration of the ships structure below the generator set. A hydrophone is also placed in the water to give an indication of the underwater noise due to the generator. The control strategy employed is six-input and six-output decentralized adaptive feedforward control with the reference signal being derived from the signal from an optical tachometer on shaft between the engine and the generator. To suppress the vibration at all the dominant forcing frequencies, an electrical circuit generated the half engine orders required from the measured reference signal. The experimental results show that the combination of the active control system and the passive isolators is effective in reducing the global vibration and the acoustic pressure at the hydrophone position.
\end{abstract}

Keywords: active vibration isolation; underwater noise radiation; experimental investigation; diesel generator; tugboat

\section{Introduction}

Vibration generated by propulsion machinery, ships' services, and auxiliary machinery, for example diesel generators, is one of the five principal groups of radiated noise sources in ships [1]. Much of this noise stems from vibration, which propagates through the structure as structure-borne noise. This means that passive vibration isolators are used extensively to suspend many vibration sources to attenuate vibration transmission. Passive isolators are extremely effective, but there is a trade-off between making them sufficiently soft to adequately attenuate low frequency vibrations and making them sufficiently stiff to ensure correct positioning of the suspended machines [2]. In addition, the damping requirement is different for low and high frequencies. Generally, high damping is required for low frequency isolation and low damping is required for high frequency isolation.

To improve the vibration isolation performance, especially at low frequencies, active vibration isolation has been proposed [2-9]. Secondary vibration sources (actuators), generate control forces to counteract the primary vibration transmission. They are often installed in series or parallel with passive resilient isolators. The actuators, together with the sensors and controller, are collectively called an active vibration isolation system. 
An active vibration isolation system has been implemented on a diesel engine in a training ship named "Fukae Maru III", where four hydraulic actuators were installed in parallel with passive isolators to reduce vibration transmission [3]. Yang et al., [5,6] developed similar active engine mounts by employing hydraulic actuators, but using an adaptive multi-notch filtered control algorithm, instead of the learning method used in [3]. Similar to a pneumatic type actuator described in [4], a hydraulic actuator can generate large forces but has a limited frequency range. Moreover, these types of actuator also need air or oil supply, resulting in a weight, and space penalty. Electromagnetic type actuators are widely used in active vibration control since they are compact and have a wide bandwidth. An example of such a device to control the transmission of vibration from a diesel engine was described in [7]. They used a coil and a magnet which were fixed on the diesel engine and the receiving structure, respectively.

An inertial shaker (or proof-mass actuator) is another kind of electrodynamic actuator which only has to be connected at one point on the structure as it generates a force by vibrating the proof-mass $[2,8,10,11]$. It is most effective at its natural frequency, but it can be used over a range of frequencies with less efficiency. It can also suffer from nonlinear behavior if the displacements of the proof-mass are large.

An alternative to the electrodynamic transduction mechanism is the use of piezoelectric elements. They can be arranged as a stack actuator and used in active engine mounts [12-14]. Piezoelectric actuators can have a very high bandwidth, generate a high force, but the displacement is generally very small. They often require an amplitude enlargement mechanism which will result in a reduction in the force generated [15]. However, the application of piezoelectric actuators opens the possibilities for compact designs and a high level of integration. As such, they have been used in the automobile rather than the marine sector $[16,17]$.

Different type of actuators and their uses in an active vibration isolation system have been compared and discussed in [7]. They suggested that a hydraulic actuator has a detrimental influence on the total stiffness. The high frequency vibration, which is not the target of control, passes through the oil since the actuator has a small, low frequency bandwidth. In Yang's work [5,6], he demonstrated that it was possible to achieve good performance at low frequencies but found that amplification occurred at higher frequencies because of nonlinearities in the hydraulic system. This was followed up by work to take the nonlinearity of the hydraulic actuator into account, and a modified adaptive control algorithm with nonlinear secondary path compensation was adopted to improve the performance of the active control system [18-20].

Compared to piezoelectric and hydraulic actuators, electromagnetic actuators are easier to put into practice $[9,21,22]$, and are accordingly used in the experiments described in this paper. Much previous published research on active vibration isolation has involved theoretical and/or laboratory-based studies. Some of the authors of this paper have attempted large-scale experiments in the laboratory [23], which have been followed up by experiments on a diesel generator on-board the tugboat featured in this paper $[24,25]$. The results demonstrated that reduction in vibration of the hull structure below the generator was possible, as was the output of a hydrophone suspended in the water near the boat. However, the vibration and underwater noise were not as well controlled as expected. This was due to a poor design of the inertial actuators, which meant they were ineffective at low frequency, and a reference signal that lacked the half engine order frequency components evident in the vibration responses.

In this paper, the deficiencies of the previous system have been rectified, with new, improved inertial shakers being deployed, together with an electrical circuit to generate the half engine orders required to suppress the vibration at the dominant forcing frequencies. Inertial shakers have been specifically employed because the active isolation system was designed to be retrofitted to an existing marine installation, in which minimum modifications were allowed and space for the system was very limited.

The paper is organized as follows. Following this introduction, the experimental set up is described in terms of both the hardware and software in Section 2. The experimental results along 
with a discussion of the results is presented in Section 3, and some specific and general conclusions are drawn in Section 4.

\section{The Active Vibration Isolation System}

\subsection{System Layout}

The tugboat, which was the platform for the active control system, is shown in Figure 1a. It is equipped with two six-cylinder, four-stroke 6135 diesel engines, at the stern. Each engine drives a generator which delivers $110 \mathrm{~kW}$ at 220 Volts alternating current. The mass of each diesel generator set is approximately $2000 \mathrm{~kg}$. Each engine is attached to the hull by six BE-400 resilient isolators. The active control system was fitted to one of the generator sets to determine its potential in a practical marine environment. A photograph of the arrangement can be seen in Figure 1b. As there is limited space in the generator room, it was decided to use bespoke electrodynamic inertial shakers as the control actuators. Six inertial actuators were located as close as possible to each isolator, with each actuator being bolted to the lower frame of the generator set, above an isolator, via a very stiff steel plate. Three of the actuators fitted to one side of the engine are marked A in Figure 1b. Also shown in the figure is the optical tachometer to provide a reference signal for the active control system, which is marked $\mathbf{B}$, the half-order generator (which is discussed later), which is marked $\mathbf{C}$, and the forced ventilation system to cool the actuators, which is marked $\mathbf{D}$. Six acceleration sensors (not shown in the figure) were placed on the bolt heads of the isolators to act as error sensors for the control system. These positions were chosen as they were as close as possible to the isolators through which the vibration is transmitted to the hull. To monitor the effectiveness of the vibration isolation system (both active and passive), six accelerometers were attached to the structure beneath each isolator. To give an indication of the radiated sound in the water, a hydrophone was suspended in the water near the boat.

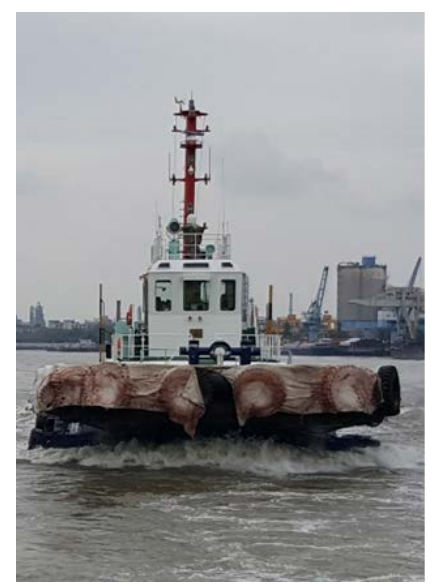

(a)

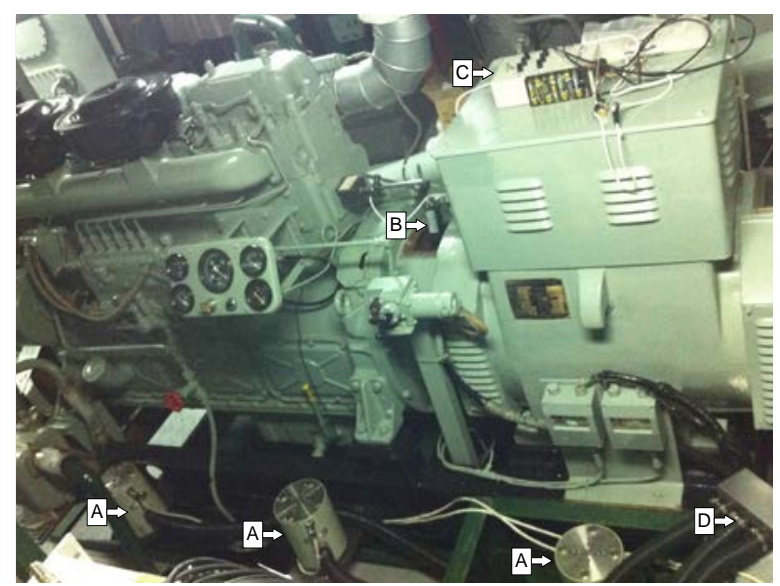

(b)

Figure 1. Photographs of: (a) The tugboat, (b)Housing the generator whose vibrations were controlled using the inertial actuators marked A. The tachometer, marked B provided the reference signal for the active control system. The half order generator, marked $C$. The forced ventilation system, marked D to cool the actuators.

A schematic diagram and photograph of an inertial actuator can be seen in Figure 2. It is an EET-020 type inertial actuator made by Suzhou Dongling Tech. Each actuator has a diameter of $140 \mathrm{~mm}$ and a length of $224 \mathrm{~mm}$. They each have a $6.5 \mathrm{~kg}$ inertial mass, and can generate $130 \mathrm{~N}$ force at their natural frequency of $10 \mathrm{~Hz}$ with about $10 \mathrm{~W}$ electrical power. 


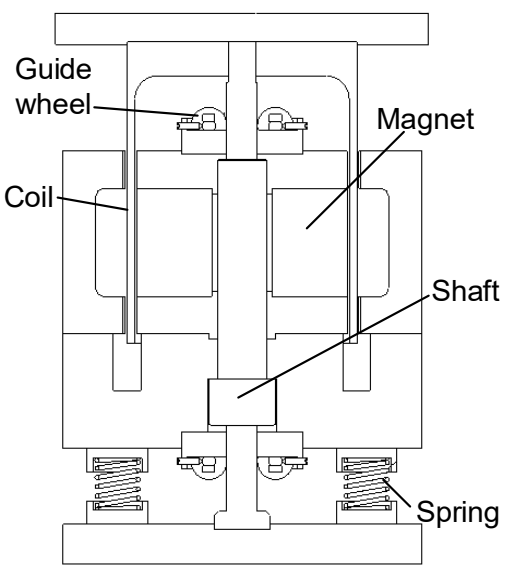

(a)

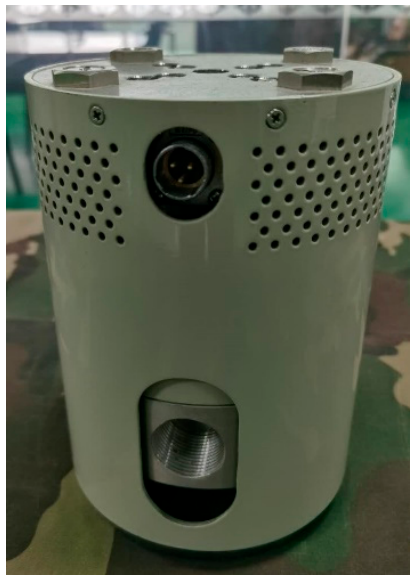

(b)

Figure 2. (a) Schematic diagram and (b) photograph of the inertial actuator.

\subsection{Control System}

Diagrams of the adaptive control system and the hardware are shown in Figure $3 \mathrm{a}, \mathrm{b}$ respectively. The input to the control system is the reference signal, $x(n)$, as can be seen in Figure $3 \mathrm{a}$. The raw output from the tachometer contains the fundamental frequency (first order) and harmonics (higher orders). However, half orders of the engine speed are necessary because the engine is a four-stroke diesel. A circuit to generate half orders was designed using a filter to allow only one pulse out of every two pulses to pass. This is shown in Figure $1 b$ and is marked B. The spectrum of the resulting signal together with that from the original signal are shown in Figure 4 for an operating speed of $1500 \mathrm{rpm}$ (which corresponds to the 1st harmonic at a frequency of $25 \mathrm{~Hz}$ ). The signals are passed through a low-pass filter set to $200 \mathrm{~Hz}$, which is the maximum frequency considered in the control process.

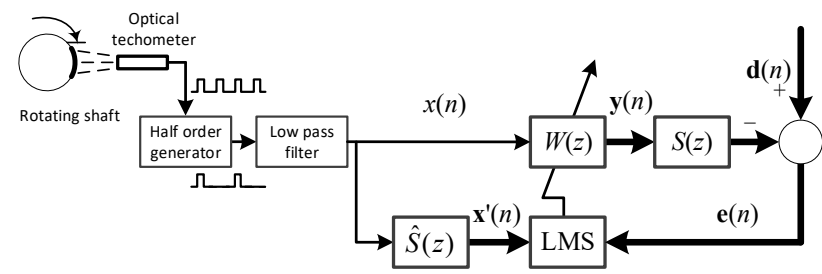

(a)

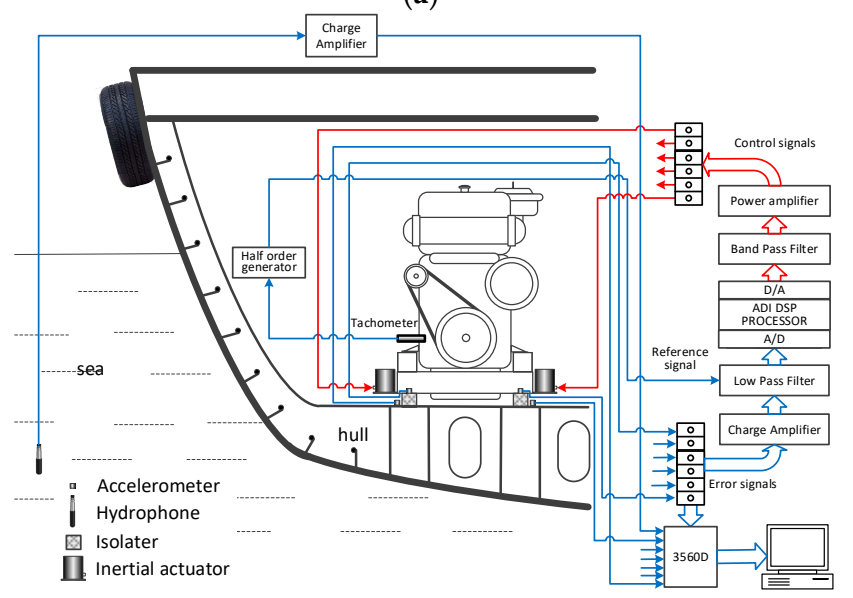

(b)

Figure 3. (a) A block diagram of the adaptive control system and (b) a schematic diagram of the control system showing the hardware. 


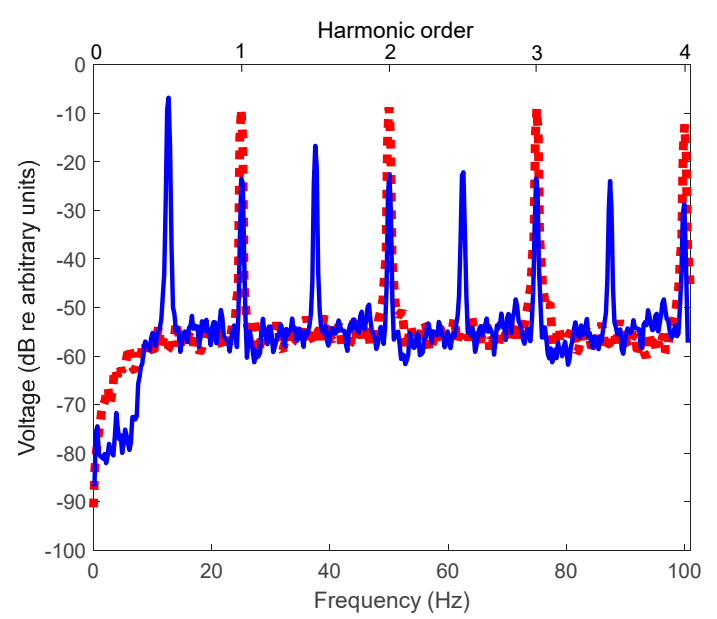

Figure 4. Spectrum of the reference signal. Red dotted line, original measured signal; blue solid line, modified reference signal with the half-order components included.

The adaptive control system, whose block diagram is in Figure 3a, is a six-input and six-output control system based on the $\mathrm{x}$-LMS algorithm $[24,25] ; x(n)$ is the reference signal, $W(z)$ is the controller filter, $\mathbf{y}(n)$ is the controller output vector, $S(z)$ is the secondary path, $\mathbf{d}(n)$ is the desired signal vector which consists of vibration responses from the six error sensors without control, $\mathbf{e}(n)$ is the error signal vector which consists of vibration responses from the six error sensors after control, and $\mathbf{x}^{\prime}(n)$ is the vector of the reference signal after being filtered by the estimated secondary path, $\hat{S}(z)$.

As shown in Figure 3b, the outputs of the controller pass through band-pass filters and power amplifiers to drive the six inertial actuators. Outputs from the six error sensors pass through charge amplifiers and low-pass filters, and are fed into the controller as error signals. An ADI DSP-based hardware system is used as the controller.

As discussed in [11], the performance of an active vibration control system depends largely upon the transfer functions of the secondary paths, so the effects of secondary paths must be compensated for by passing the reference signal through the estimated secondary path filters, which are denoted by $\hat{S}(z)$ in Figure 3a.

A secondary path is the path between a controller output signal and an error signal, including the D/A (digital-to-analogue) converter, band-pass filter, power amplifier, actuator, physical system from the actuator location to the error sensor position, the error sensor itself, charge amplifier, low-pass filter and A/D (analogue-to-digital) converter. The impulse responses between the first inertial actuator to all six error sensors are shown in Figure 5a. It can be seen that the driving point impulse response function (IRF) is much larger than the transfer IRFs, which means that the secondary paths are weakly coupled. This, in turn, means that a decentralized control system could be implemented, drastically reducing the complexity. Six independent adaptive x-LMS-based filters are used, which are described by the equations $[22,26]$

$$
\left\{\begin{array}{l}
y_{i}(n)=\mathbf{w}_{i}^{\mathrm{T}}(n) \mathbf{x}(n)=\sum_{l=0}^{L-1} w_{i, l} x(n-l) \\
e_{i}(n)=d_{i}(n)-s_{i}(n) * y_{i}(n) \\
\mathbf{w}_{i}(n+1)=\mathbf{w}_{i}(n)+\mu_{i} \mathbf{x}^{\prime}{ }_{i}(n) e_{i}(n) \\
\mathbf{x}^{\prime}{ }_{i}(n)=\left[x_{i}^{\prime}(n), x_{i}^{\prime}(n-1), \ldots, x^{\prime}{ }_{i}(n-L+1)\right]^{\mathrm{T}} \\
x^{\prime}{ }_{i}(n)=\sum_{h=0}^{H-1} \hat{s}_{i, h} x(n-h)
\end{array},\right.
$$

where $n$ is iteration number, $s_{i}(n)(i=1-6)$ is the IRF of the $i$-th secondary path, $y_{i}(n)$ is the $i$-th controller output signal, ${ }^{*}$ denotes convolution, $L$ is the tap number of the adaptive control filters, $H$ is the number of taps of the estimated secondary path filters, here $L=H=256, \mu_{i}(n)$ is the convergence 
coefficient of the adaptive filter, $\mathbf{x}_{i}(n), \mathbf{w}_{i}(n), \hat{\mathbf{s}}_{i}(n)$ are the reference input signal vector, $i$-th controller filter vector, and $i$-th estimated secondary path filter vector respectively, which can be expressed as

$$
\begin{gathered}
\mathbf{x}(n)=[x(n), x(n-1), \ldots, x(n-L+1)]^{\mathrm{T}}, \\
\mathbf{w}_{i}(n)=\left[w_{i, 0}, w_{i, 1}, \ldots w_{i, l}, \ldots, w_{i, L-1}\right]^{\mathrm{T}}, \\
\hat{\mathbf{s}}_{i}(n)=\left[\hat{s}_{i, 0}, \hat{s}_{i, 1}, \ldots, \hat{s}_{i, h}, \ldots, \hat{s}_{i, H-1}\right]^{\mathrm{T}},
\end{gathered}
$$

The six secondary paths were modeled using 256-tap adaptive finite impulse response (FIR) filters, which were calculated by adaptive system identification measurements with the same sampling frequency of $1.5 \mathrm{kHz}$ as the active control process. The impulse response functions of the first secondary path derived by an adaptive modeling process and the commercial equipment are shown in Figure $5 \mathrm{~b}$. For comparison, all the IRFs modeled by the filters are shown in Figure 6. It can be seen that 256 taps are enough to describe the dynamic characteristics of the secondary paths.

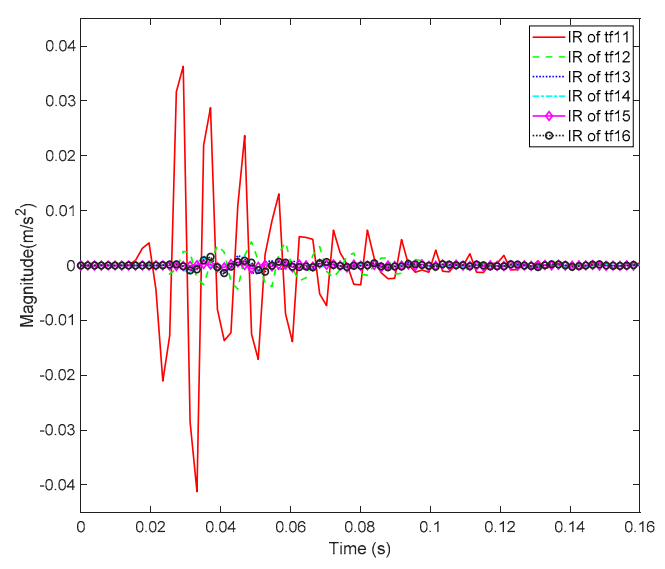

(a)

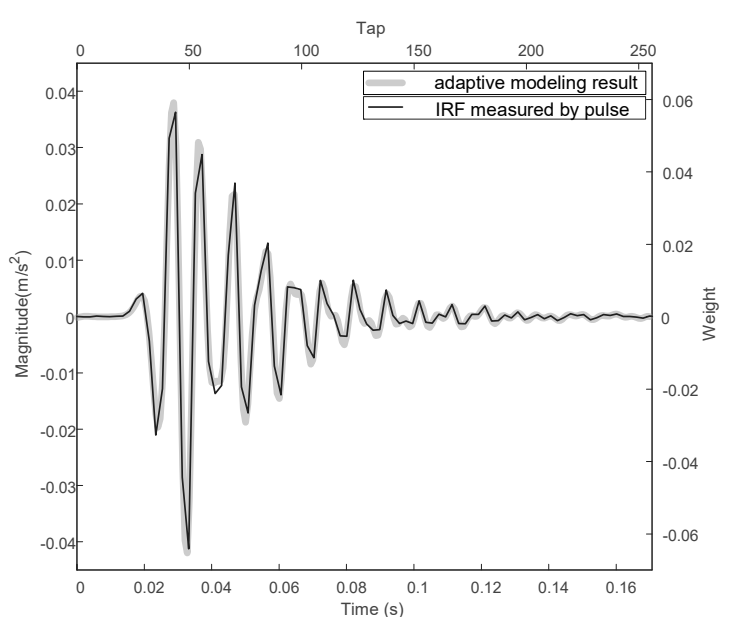

(b)

Figure 5. The impulse responses of: (a) The secondary paths between inertial actuator 1 and the six error sensors, (b) The first secondary path derived from the adaptive modeling result and measured by pulse software.

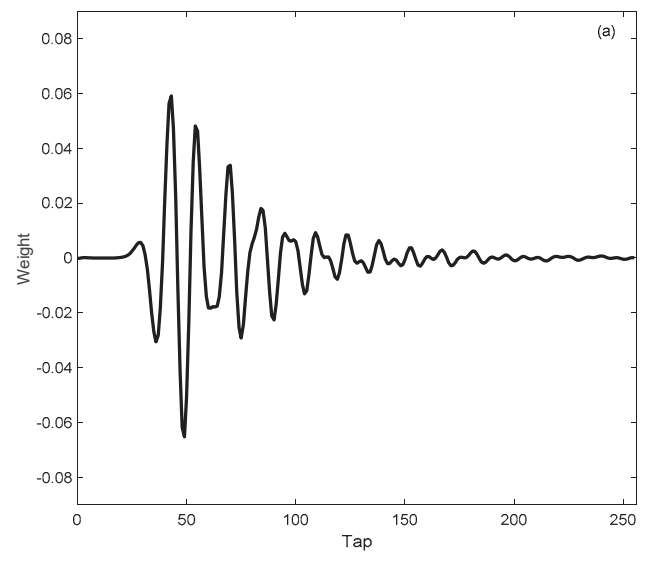

(a)

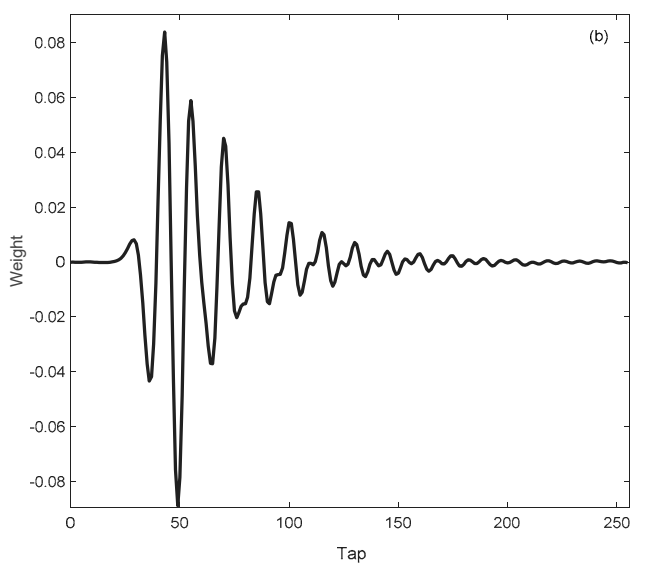

(b)

Figure 6. Cont. 


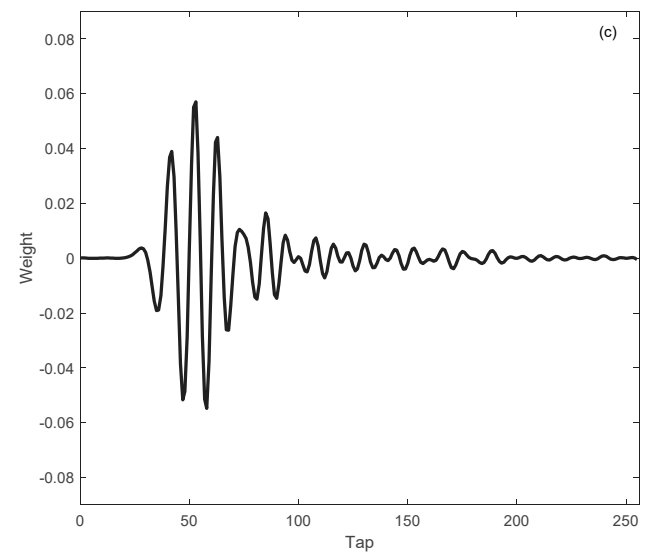

(c)

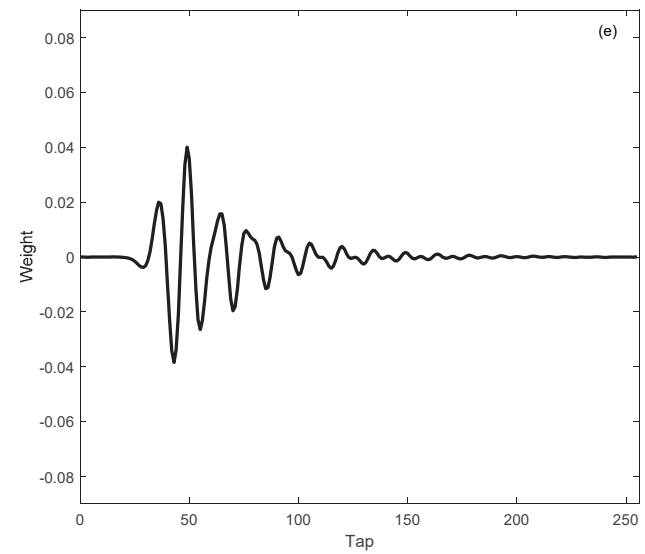

(e)

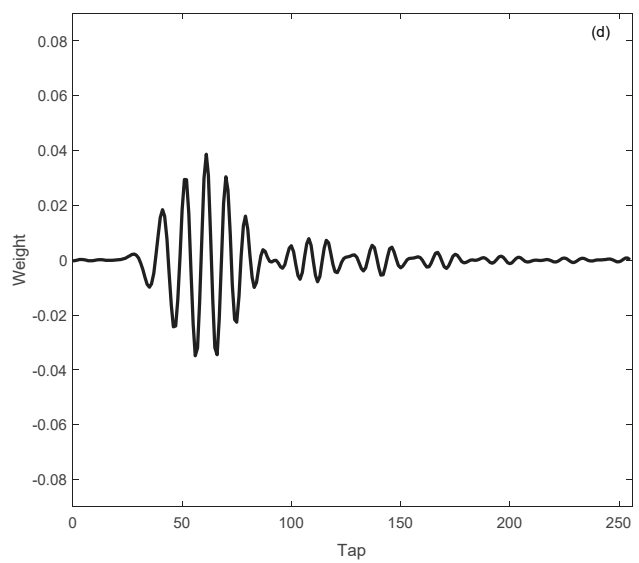

(d)

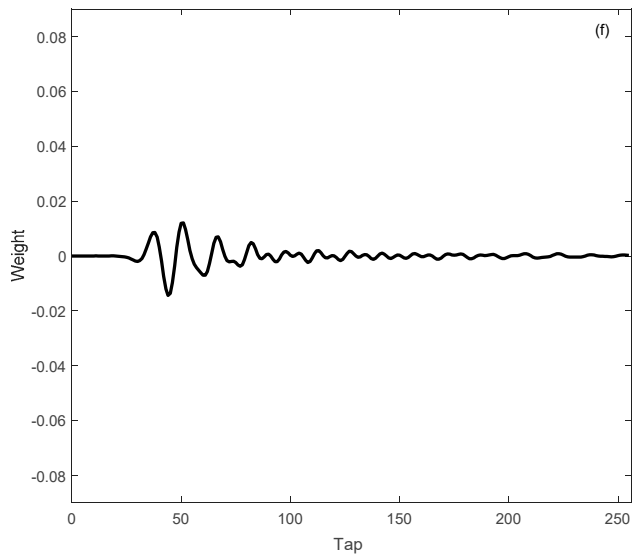

$(\mathbf{f})$

Figure 6. The impulse responses of the secondary paths modeled by FIR filters: $(\mathbf{a}-\mathbf{f})$ are the first to sixth secondary paths respectively.

\section{Results and Discussion}

Active vibration isolation experiments were conducted on a single generator set running at $1500 \mathrm{rpm}$, which is the normal operating condition. Measurements were made with the active control system switched both off and on, and the results are presented in Figures 7 and 8. Figure 7a shows the spectra of square root of the mean square acceleration responses above and below the isolators, with and without the active control system operating. The dominant responses at integer multiples of half engine orders are evident, and as these orders are contained in the reference signal, the active control system can target these frequencies. It is clear from Figure $7 \mathrm{a}$ that above about $20 \mathrm{~Hz}$, the passive isolators are very effective in attenuating vibration transmission to the hull over the whole of the frequency range, with an average reduction of about $30 \mathrm{~dB}$ at most frequencies. With the exception of the frequency of $12.5 \mathrm{~Hz}$, which corresponds to the first half engine order, the active control system results in vibration reduction at frequencies corresponding to all the half orders. For the vibration levels beneath the isolators, there is a small degree of amplification at frequencies corresponding to first half order and the fourth order, and a negligible change at frequencies corresponding to the sixth, seventh, and eighth orders. At frequencies corresponding to all the other half orders, the active control system is effective, but its efficacy varies between the engine orders. 


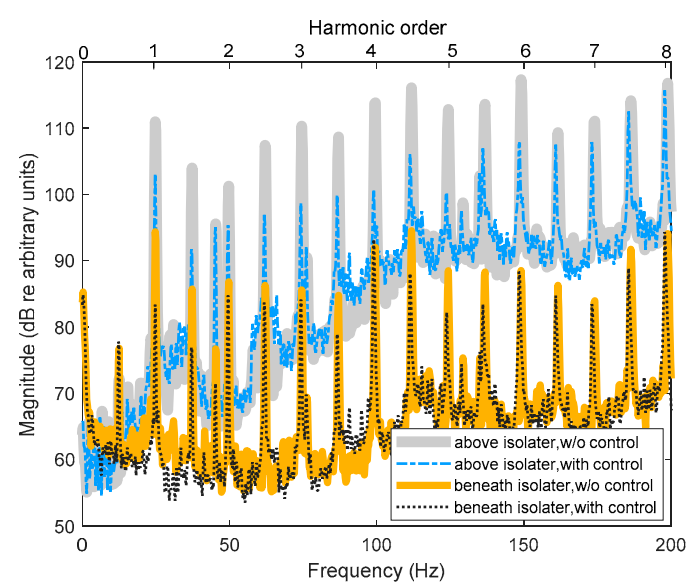

(a)

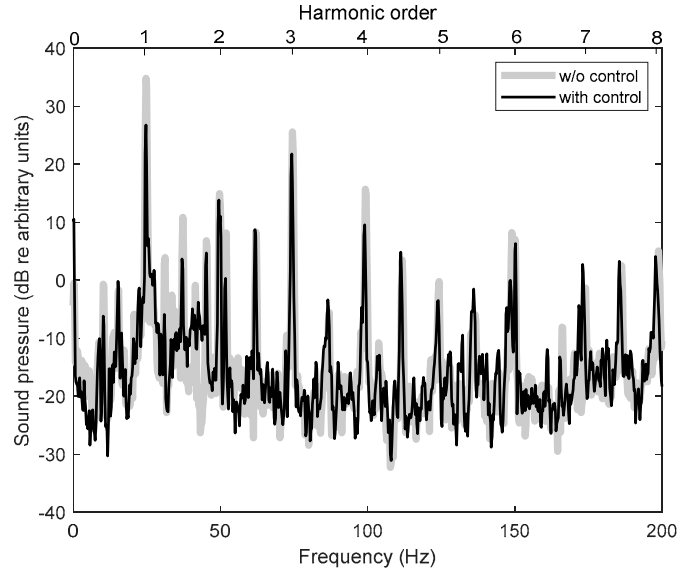

(b)

Figure 7. Experimental results: (a) Spectra of vibration with and without control, (b) Acoustic pressure in the water with and without control.

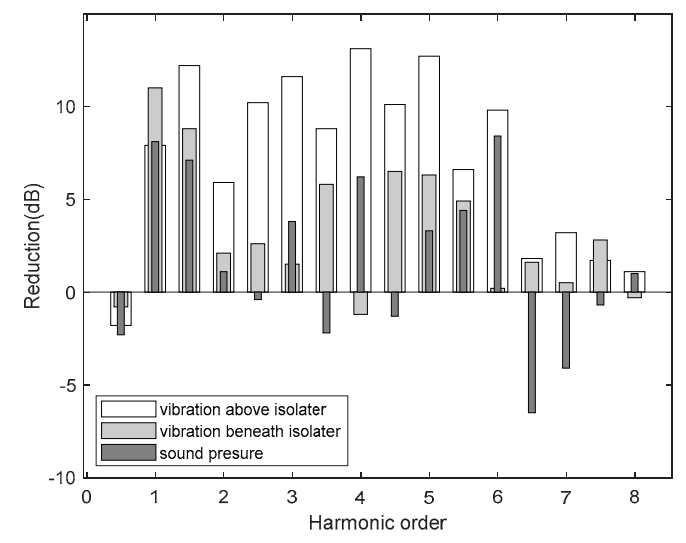

Figure 8. Effectiveness of the active control at each engine half-order.

The spectrum of the hydrophone output is shown in Figure $7 \mathrm{~b}$ for the active control system switched both off and on. The results show that in general, the half engine orders dominate the spectrum, with the active control system being effective at some frequencies but has a detrimental effect at others. To see more clearly the effectiveness of the active control system, the reductions at the frequencies corresponding to the half orders for the accelerations above and below the isolators and the acoustic pressure in the water, are plotted in Figure 8. It can be seen that all vibration levels and the sound pressure level have marginally increased at $12.5 \mathrm{~Hz}$, which corresponds to the first half-order. At higher frequencies, up to the sixth engine order the reductions in vibration above the isolator range from between 5 and $10 \mathrm{~dB}$. The reductions in vibration below the isolators is more modest, which is probably because the actuators only act on this vibration through the isolators by controlling the vibration above the isolators. The reductions in the sound pressure are even more modest, with some amplification occurring at some frequencies, especially at the sixth and a half order and the seventh order. Caution should be exercised in drawing strict conclusions concerning the sound reduction, however, as only a single point measurement was made in this case, whereas estimates of the global vibrations were made using six accelerometers above and below the isolators.

\section{Conclusions}

This paper has investigated the performance of an active vibration isolation system fitted to a diesel generator in a floating tugboat. The system was fitted to the generator set without making any changes to the existing machinery layout. It thus effectively complemented the existing passive 
vibration isolation system. This system consisted of six inertial electrodynamic actuators and a DSP-based controller employing an adaptive feedforward control strategy. The reference signal for the controller was derived from an optical tachometer on the shaft between the engine and the generator. The signal was passed through a half-order generator to generate all the harmonics in the vibration response. Using the responses from six accelerometers placed next to the actuators, a six-input and six-output decentralized adaptive control strategy was adopted. Six accelerometers were also placed directly below the passive isolators to give a measure of the hull vibration below the generator, and a hydrophone was placed in the water to give an indication of the sound radiated. The active vibration isolation experiment was conducted when only the diesel engine generator was working in the tugboat.

The experimental results show that the combination of the active control system and the passive isolators is effective in reducing the global vibration on the frames below the generator, with vibration reductions of more than $10 \mathrm{~dB}$ at several engine orders when the active control system is switched on. The reduction in the acoustic pressure at the hydrophone position due to active control is up to $8 \mathrm{~dB}$ for some engine orders although there is a marginal increase at some other frequencies.

Overall, the study has demonstrated that a self-contained active control system can be retrofitted to a marine diesel generator set where there is limited space. Using inertial actuators and accelerometers, it has been shown that it is possible to achieve appreciable attenuation of the vibration transmitted to the hull at integer multiples of the half engine orders, complementing the attenuation due to the passive vibration isolators. As the active control system proved to be effective on one generator set, the next step in this work is to extend the system to both generator sets, and then to perform trials in harbor and then at sea.

Author Contributions: Methodology, T.Y. and X.L.; software and validation, M.Z. and X.L.; experimental work, T.Y., L.W., M.Z. and X.L.; writing—original draft preparation, L.W.; writing—-review and editing, T.Y. and M.J.B.; supervision, Z.L. All authors have read and agreed to the published version of the manuscript.

Funding: This research was funded by the National Natural Science Foundation of China, No. 51375103.

Conflicts of Interest: The authors declare no conflict of interest.

\section{References}

1. Crocker, M.J. Handbook of Noise and Vibration Control; John Wiley \& Sons, Inc.: Hoboken, NJ, USA, 2007; pp. 1216-1232.

2. Winberg, M.; Hansen, C.; Claesson, I.; Li, X. Active Control of Engine Vibration in a Collins Class Submarine; Blekinge Institute of Technology Research Report No 2003:11; Blekinge Institute of Technology: Karlskrona, Sweden, 2003.

3. Mitsuhashi, K.; Biwa, T.; Mizuhara, S.; Sugiura, K. Application of active vibration isolating system to diesel engine mounting. In Proceedings of the 18th International Congress on Combustion Engines, Diesel Engines, Tianjin, China, 5-8 June 1989; Volume 281-300.

4. Day, M.J.; Randall, R.J.; Ratcliffe, C.P.; Rider, E. Reducing the vibrations caused by a marine diesel generator set. Proc. Inst. Mech. Eng. Part C J. Mech. Eng. 1993, 207, 375-381. [CrossRef]

5. Yang, T. Active Vibration Isolation Technique for Diesel Plant. Ph.D. Thesis, Harbin Engineering University, Harbin, China, 2001.

6. Yang, T.; Zhang, X.; Xiao, Y.; Huang, J.; Liu, Z. Adaptive vibration isolation system for marine engine. J. Mar. Sci. Appl. 2004, 3, 30-35. [CrossRef]

7. Moriyuki, S.; Eiichi, Y.; Kubota, T.; Wada, H.; Sakurai, H. Active vibration isolation of a diesel engine generator with linear voice coil motors. In Proceedings of the 24th CIMAC Congress on Combustion Engines, Kyoto, Japan, 7-11 June 2004.

8. Winberg, M.; Johansson, M.; Håkansson, L.; Claesson, I.; Lagö, T. Active vibration isolation in ships: A pre-analysis of sound and vibration problem. Int. J. Acoust. Vib. 2005, 10, 175-196. [CrossRef]

9. Li, Y.; He, L.; Shuai, C.; Ni, Y. Vibration isolation technology for ship machinery using electromagnetic actuator and air spring. Acta Acust. 2015, 40, 751-760. 
10. Daley, S.; Johnson, F.A.; Pearson, J.B.; Dixon, R. Active control for marine applications. Control Eng. Pract. 2000, 12, 465-474. [CrossRef]

11. Orivuori, J.; Zazas, I.; Daley, S. Active control of frequency varying disturbances in a diesel engine. Control Eng. Pract. 2012, 20, 1206-1219. [CrossRef]

12. Sumali, H.; Cudney, H.H. An active engine mount with a piezoelectric stacked actuator. In Proceedings of the 35th Structures, Structural Dynamics, and Materials Conference, Hilton Head, SC, USA, 18-20 April 1994.

13. Matthias, M.; Friedmann, A.; Koch, T.; Drögemüller, T. Active mounts for marine application: The BMBF research project: Active aggregate mounts to reduce structure vibrations and structure-borne sound transmission. In Proceedings of the Active and Passive Smart Structures and Integrated Systems, San Diego, CA, USA, 19-22 March 2007.

14. Matthias, M.; Mayer, D.; Herold, S. Active mounts for marine application: The BMWi research project, Active aggregate mounts to reduce structure vibrations and structure borne sound transmission. In Proceedings of the 11th International Conference on New Actuators (Actuator 2008), Bremen, Germany, 9-11 June 2008.

15. Garcia-Bonito, J.; Brennan, M.J.; Elliott, S.J.; David, A.; Pinnington, R.J. A novel high displacement piezoelectric actuator for active vibration control. Smart Mater. Struct. 2008, 7, 31-42. [CrossRef]

16. Mayer, D.; Herold, S.; Stücklschwaiger, W.; Thomann, S.; Zhang, C. Realisation and test of an active engine mount system for automotive applications. In Proceedings of the 5th International Styrian Noise, Vibration \& Harshness Congress, Graz, Austria, 4-6 June 2008.

17. Herold, S.; Kraus, R.; Millitzer, J.; Rue, G. Vibration control of a medium-sized vehicle by a novel active engine mount. In Proceedings of the 4th PT PIESA Symposium, Nuremberg, Germany, 26-27 March 2013.

18. Liu, Z.; Yang, T.; Du, J.; Liu, X.; Jin, G.; Suai, Z.; Li, W. Active vibration isolation system for diesel engine. In Proceedings of the 37th International Congress and Exhibition on Noise Control Engineering (INTER-NOISE 2008), Shanghai, China, 26-29 October 2008.

19. Xiao, B. Study on Active Isolation Technology for Diesel Two-Stage Vibration Isolation Mounting. Ph.D. Thesis, Harbin Engineering University, Harbin, China, 2008.

20. Yang, T.; Suai, Z.; Sun, Y.; Zhu, M.; Xiao, Y.; Liu, X.; Du, J.; Jin, G.; Liu, Z. An active vibration isolation system for a diesel engine. Noise Control Eng. J. 2012, 60, 267-282. [CrossRef]

21. Active Control Systems of Noise and Vibrations. Available online: https://www.paulstra-industry.com/ upload/product/documentation/supports-actifs-uk.pdf (accessed on 22 January 2020).

22. Yang, T.; Shi, H.; Li, X.; Zhu, M.; Wu, G.; Liu, Z. One active isolation system for marine machine based on smart isolators. J. Vib. Eng. 2017, 30, 167-176.

23. Yang, T.; Sun, Y.; Zhou, L.; Brennan, M.J.; Liu, Z. Practical demonstration of a large-scale active vibration isolation system. Case Stud. Mech. Syst. Signal Process. 2015, 1, 32-37. [CrossRef]

24. Yang, T.; Li, X.; Zhu, M.; Du, J.; Liu, X.; Liu, Z. Experimental investigation of active vibration control for diesel engine generators in marine applications. J. Vib. Eng. 2013, 26, 160-168.

25. Yang, T.; Du, J.; Zhu, M.; Liu, X.; Liu, Z. Active vibration isolation for a diesel engine generator in marine application. In Proceedings of the 27th CIMAC Congress, Shanghai, China, 13-16 May 2013.

26. Burgess, J. Active adaptive sound control in a duct: A computer simulation. J. Acoust. Soc. Am. 1981, 70, 715-726. [CrossRef]

(C) 2020 by the authors. Licensee MDPI, Basel, Switzerland. This article is an open access article distributed under the terms and conditions of the Creative Commons Attribution (CC BY) license (http://creativecommons.org/licenses/by/4.0/). 